\title{
Dysmenorrhea and Associated Factors among Polish Women: A Cross-Sectional Study
}

\author{
Zofia Barcikowska (D), ${ }^{1}$ Karolina Wójcik-Bilkiewicz $(\mathbb{D}),{ }^{2}$ Agnieszka Sobierajska-Rek (D), ${ }^{3}$ \\ Magdalena Emilia Grzybowska $\left(\mathbb{D},{ }^{4}\right.$ Piotr Wąż ${ }^{1},{ }^{5}$ and Katarzyna Zorena ${ }^{1}{ }^{1}$ \\ ${ }^{1}$ Department of Immunobiology and Environment Microbiology, Medical University of Gdańsk, Dębinki 7, 80-211, \\ Gdańsk, Poland \\ ${ }^{2}$ Department of Clinical Anatomy, Medical University of Gdańsk, Dębinki 1, 80-211, Gdańsk, Poland \\ ${ }^{3}$ Department of Rehabilitation Medicine, Medical University of Gdańsk, Al. Zwycięstwa 30, 80-219, Gdańsk, Poland \\ ${ }^{4}$ Department of Gynecology, Gynecological Oncology and Gynecological Endocrinology, Medical University of Gdańsk, \\ Smoluchowskiego 17, 80-214, Gdańsk, Poland \\ ${ }^{5}$ Department of Nuclear Medicine, Medical University of Gdańsk, Tuwima 15, 80-210, Gdańsk, Poland
}

Correspondence should be addressed to Zofia Barcikowska; zofia.barcikowska@gumed.edu.pl

Received 12 January 2020; Revised 19 April 2020; Accepted 1 June 2020; Published 11 July 2020

Guest Editor: Ji Tu

Copyright (c) 2020 Zofia Barcikowska et al. This is an open access article distributed under the Creative Commons Attribution License, which permits unrestricted use, distribution, and reproduction in any medium, provided the original work is properly cited.

\begin{abstract}
Purpose. The aim of the research was to conduct an assessment of the prevalence of dysmenorrhea and associated factors among Polish women. Patients and Methods. A cross-sectional study was conducted among Polish women using an online questionnaire. The mean age of the participants was $23 \pm 4$ years. Out of the total of 1,317 women who took part in the study, 1,127 were included in the analysis, and 190 were excluded due to incomplete answers. The questionnaire consisted of 19 questions that were grouped into three parts. The first concerned sociodemographic data such as age, weight, education, and residence (urban or rural). The second part of the questionnaire pertained to the factors of dysmenorrhea (premenstrual syndrome, age of menarche, and family history of dysmenorrhea.). In the third part, the women were asked about their diet, alcohol intake, cigarette smoking, and physical activity. Results. Dysmenorrhea affected $94 \%$ of the interviewed women. Dysmenorrhea was most likely to occur among respondents whose mothers had a history of dysmenorrhea $(p<0.005)$. Significant relationship between the occurrence of dysmenorrhea among respondents and their sisters was also observed $(p<0.005)$. The prevalence of premenstrual syndrome (PMS) was significantly higher in women reporting dysmenorrhea $(p<0.005)$. Other significant factors associated with dysmenorrhea were age of menarche $(p<0.005)$, stress frequency $(p=0.005)$, lack of physical activity $(p=0.037)$, and self-esteem $(p=0.042)$. However, in the respondents, no significant relationship was observed between dysmenorrhea and diet, smoking, body mass index, and alcohol intake. Conclusion. The study points to the fact that the problem of dysmenorrhea affects many Polish women. Women with dysmenorrhea were characterized with a family history of dysmenorrhea, occurrence of PMS, early age of menarche, stressful lifestyle, lack of physical activity, and low self-esteem. We suggest that further assessment of factors contributing for dysmenorrhea among women is necessary.
\end{abstract}

\section{Introduction}

Dysmenorrhea, also known as painful periods, is a syndrome resulting in painful cramps during menstruation [1]. Dysmenorrhea often occurs among young women and often compounds their quality of life. A great majority of women are forced to miss full days off school or work, due to dysmenorrhea, and have difficulty concentrating on daily activities [1-3]. The women with dysmenorrhea often report cancelling social meetings, have difficulties falling asleep, or feel depressed and irritated during menstruation [2, 3]. According to the World Health Organization (WHO) data, dysmenorrhea affects between $1.7 \%$ and $97 \%$ of women [4]. In the two existing Polish epidemiological studies, it was 
demonstrated that dysmenorrhea is experienced by $65 \%$ of Polish women $[5,6]$.

Dysmenorrhea is classified as primary and secondary [2]. Primary dysmenorrhea is attributable to excessive, pathological uterine contractions, without any other pathologic changes in the area of the pelvis minor [2]. Most commonly it appears earlier than 12 months after menarche. The pain often occurs during the first 8-72 hours [2]. Secondary, dysmenorrhea is associated with a prevalence of acquired changes, such as endometriosis, chronic inflammatory condition of the pelvis minor, uterine fibroids, endometrial polyps, and cervix stenosis, as well anatomical and functional abnormalities of the generative organs $[1,3]$. Usually, dysmenorrhea affects women aged 20-25, often easing off after the first pregnancy $[7,8]$. During the menstrual cycle, discomfort starts a few hours before or directly with the menses. The pain is characterized as systolic, often radiating towards the groin, back, or thighs [3,9]. Abdominal pain may be accompanied by other symptoms, such as nausea, headache, back pain, diarrhoea, or fatigue $[3,10]$.

Despite many studies on dysmenorrhea, the etiopathogenesis of this condition has not been fully investigated. However, it is known that susceptibility to dysmenorrhea may be associated with genetic factors [11-13]. It is also known that the occurrence of dysmenorrhea in women is associated with an elevated secretion of prostaglandins and other inflammatory factors [3, 14, 15]. Prostaglandins stimulate excessive contractile function of the uterus, that leads to the reduction of blood flow and hypoxia of this organ. Excessive release of prostaglandins also explains the coexistence of other symptoms, such as nausea and headache $[10,16,17]$.

In addition, there are more scientific reports about factors that may predispose women to the occurrence of pain during menstruation, including body mass index (BMI), socioeconomic situation, dietary habits, and stress levels, although the research results are contradictory $[6,18,19]$. Therefore, the purpose of this cross-sectional study was to assess the prevalence of dysmenorrhea and related factors among Polish women.

\section{Materials and Methods}

2.1. Design and Data Collection. This was a cross-sectional study conducted among Polish women using an online questionnaire. A web-based survey available through Google forms was completed by 1,317 respondents. The information about the study was spread by social media, and the questionnaire was available as open access. An informed consent was obtained in the first page of the study's questionnaire. It explained the aims of the study, emphasized the confidentiality of the filled out information, and provided information about the affiliation of the researchers. Participants were able to withdraw from the study at any point. No identifying information was obtained through the questionnaire, and all collected data were solely used for the statistical analysis. The questionnaire was prepared with reference to previous studies in the literature [20-23]. To maximize comprehension of the questionnaire, it was piloted in a sample of 10 women aged 20-35. The questionnaire was designed in Polish for the purpose of this study, and then translated into English for the purpose of publication. It consisted of 19 questions (Appendix A). Multiple choice, single-answer questions, and open questions were included. The questions were grouped into three parts. The first concerned sociodemographic data, such as age, weight, education, and residence (urban or rural). The second part of the questionnaire pertained to the factors of dysmenorrhea. The respondents were asked about the regularity of their menstrual cycles, dysmenorrhea, its intensity and duration (based on the average of all past menstrual cycles), premenstrual syndrome (PMS), menarche age, and the family history of dysmenorrhea. In the third part, the women were asked about their diet, alcohol intake, cigarette smoking, and physical activity. They were also asked to assess how often they experienced stress and how they perceived themselves: whether they were satisfied with their appearance and whether they accepted themselves or not.

The respondents' BMI was calculated based on the answers provided to questions about their height and weight. The results were divided into 3 groups based on the WHO classification: underweight $(<18.5)$, normal weight (18.5-24.9), and overweight $(25<)$ [24].

Pain severity was assessed with the use of the Numeric Pain Rating Scale (NPRS) [25]. The NPRS is an 11 point scale from 0 to 10 , where 0 indicates "no pain", and 10 indicates the "worst imaginable pain". Respondents were requested to choose a single number from the scale, that best indicates their level of pain. Only the subjects declaring dysmenorrhea assessed the intensity of pain. The analysis did not include the " 0 " points answer. Based on the literature, the pain was classified as mild, moderate, or severe. Mild pain was indicated by $1-3$ points, moderate by $4-6$ points, and severe by 7-10 points [26]. For the purpose of the analysis, the women were divided into three groups: women with dysmenorrhea during every cycle (PG), women with dysmenorrhea occasionally only (SG), and women without dysmenorrhea (WG).

2.2. Data Analysis. The results were generated using the $R$ statistics language [27]. Basic statistics (mean, standard deviation, and median) were calculated for quantitative variables. The Shapiro-Wilk test was used to test for normality. The differences between the values of more than two data sets were analysed using the Kruskal-Wallis test and the post hoc Wilcoxon rank sum test. Qualitative variables were characterized by counts and percentages. Pearson's chisquared test and Fisher's exact test for counting data were used to test the independence of these variables. The strength of the relationship between events (described by qualitative variables) was determined by calculating the odds ratios (OR) and their confidence intervals (CIs). The values given in the tables for the qualitative variables were also used to create the association diagrams [28]. The figures show, among others, the Pearson residuals and $p$ values for the independence test. In the association diagrams, the blue 
colour indicates numbers that are higher than the expected. The red colour shows cases where the numbers are smaller than the expected. In contrast, the grey colour represents the data where the numbers are close to the expected, i.e., the null hypothesis of the independence test is true. In the association chart, each cell of the contingency table is represented by a rectangle. In our work, the rectangle has a height proportional to the Pearson residual and a width proportional to the root of the expected value, thanks to which the surface area is equal to the difference between observed and expected frequencies. The rectangles in each row are set in relation to the baseline indicating independence. The correspondence analysis [29] was used to search for clusters of variables creating the tables with more than two rows and columns. The assumed significance level is $\alpha=0.05$.

\section{Results}

3.1. Sociodemographic Factors among Polish Respondents. Out of the total of 1,317 women who took part in the study, 1,127 were included in the analysis, and 190 were excluded due to incompleteness of the answers. The response rate was $93.2 \%$. The mean age of the participants was $23 \pm 4$ years. It was observed that among 1,127 respondents, 928 (82.3\%) had regular and 199 (17.7\%) irregular of menstrual cycle. The majority of the respondents were university students (54.8\%). Over $96 \%$ of the respondents lived in urban areas. Among 1,127 respondents, 1,059 (94\%) had dysmenorrhea, including 610 (54.1\%) every menstrual cycle and 449 (39.9) not every menstrual cycle. However, only 68 (6.0\%) did not experience dysmenorrhea at all (Table 1 ).

3.2. Pain Severity among Women with Dysmenorrhea. Based on the NPRS scale, the study showed that $68(6.0 \%)$ of the respondents did not experience dysmenorrhea, while 797 (70.7\%) with dysmenorrhea rated the pain as severe. Moderate pain affected 233 (20.7\%) of women, and only 29 (2.6\%) women evaluated their pain as mild (Table 2).

\subsection{Analysis of Factors Associated with Dysmenorrhea among} Respondents. Factors associated with dysmenorrhea among respondents are provide in Table 3

3.3.1. Dysmenorrhea in Mothers of the Respondents. Pearson's chi-squared test showed that dysmenorrhea was most likely to occur in respondents whose mothers had a history of dysmenorrhea $(p<0.005)$ (Table 3$)$. The odds ratio (OR) for the occurrence of dysmenorrhea in mothers of the women from the PG group in relation to mothers of the women from the WG group was 6.23 (3.33-11.64 CI). Model methods were used to analyse nonmetric variables, such as total distribution. The analysis, conducted using contingency tables, made it possible to assess the relationship between multidimensional data for the respondents from individual groups (PG, SG, and WG) and the occurrence of dysmenorrhea in the respondents' mothers (answers: yes/
TABLE 1: Sociodemographic characteristics of women participants in the study group.

\begin{tabular}{lcc}
\hline Variable & \multicolumn{1}{c}{$n(\%)$} \\
\hline \multirow{2}{*}{ Age (mean, SD) } & $23 \pm 4$ & 1127 \\
& Pupil & $25(2.2)$ \\
Education & University student & $618(54.8)$ \\
& Primary & $9(0.8)$ \\
& Secondary & $204(18.1)$ \\
Place of residence & Higher & $271(24.1)$ \\
& Rural & $39(3.5)$ \\
Regularity of cycle & Urban & $1088(96.5)$ \\
& Irregular & $199(17.7)$ \\
Dysmenorrhea & Regular & $928(82.3)$ \\
occurrence & Yes, every menstrual cycle & $610(54.1)$ \\
& Yes, not every menstrual & $449(39.9)$ \\
& cycle & $68(6.0)$ \\
\hline
\end{tabular}

Abbreviations: SD, standard deviation.

TABle 2: Pain intensity in NPRS (among women with dysmenorrhea).

\begin{tabular}{lc}
\hline & $n(\%)$ \\
\hline No pain (0) & $68(6.0)$ \\
Mild (1-3) & $29(2.6)$ \\
Moderate (4-6) & $233(20.7)$ \\
Severe (7-10) & $797(70.7)$ \\
\hline
\end{tabular}

Abbreviations: NPRS, numeric pain rating scale.

no). The analysis showed that the dysmenorrhea in mothers of the women from the WG group was less frequent than the expected value (red). However, the absence of pain in mothers of the women from the WG group was more frequent than the expected value (blue). The occurrence of dysmenorrhea in mothers of the women from the SG and PG groups as well as the absence of dysmenorrhea in mothers of the women from the SG group were in line with the expected values. The analysis of multidimensional data, conducted using contingency tables, demonstrated a statistically significant relationship $p<0.001$ (Figure 1).

3.3.2. Dysmenorrhea in Sisters of the Respondents. Pearson's chi-squared test showed that dysmenorrhea was most likely to occur in respondents whose sisters had a history of dysmenorrhea $(p<0.005)$ (Table 3$)$. The OR for the occurrence of dysmenorrhea in sisters of the women from the PG group in relation to sisters of the respondents from the WG group was $3.17(1.48-6.80 \mathrm{CI})$. In order to measure the relationship between the multivariate variables, the analysis using contingency tables was conducted for the respondents from individual groups (PG, SG, and WG) and the occurrence of dysmenorrhea in sisters of the respondents (answers: yes/ no).

Dysmenorrhea occurred less often than expected in sisters of the women from the WG group (blue). The number of sisters of the women from the PG and SG groups who had dysmenorrhea as well as those who did not suffer from 
TABLE 3: Factors associated with dysmenorrhea among respondents.

\begin{tabular}{|c|c|c|c|c|c|}
\hline & & $\begin{array}{c}\text { PG } \\
n(\%)\end{array}$ & $\begin{array}{c}\text { SG } \\
n(\%)\end{array}$ & $\begin{array}{l}\text { WG } \\
n(\%)\end{array}$ & $p$ value \\
\hline \multirow{3}{*}{$\begin{array}{l}\text { Family history of } \\
\text { dysmenorrhea, mother }\end{array}$} & Yes & $364(59.7)$ & $188(41.9)$ & $17(25.0)$ & \multirow{3}{*}{$<0.005^{*}$} \\
\hline & No & $110(18.0)$ & $89(19.8)$ & $32(47.1)$ & \\
\hline & I do not know & $136(22.3)$ & $172(38.3)$ & $19(27.9)$ & \\
\hline \multirow{4}{*}{$\begin{array}{l}\text { Family history of } \\
\text { dysmenorrhea, sister }\end{array}$} & Yes & $174(28.5)$ & $125(27.8)$ & $13(19.1)$ & \multirow{4}{*}{$<0.005^{*}$} \\
\hline & No & $76(12.5)$ & $36(8.0)$ & $18(26.5)$ & \\
\hline & I do not know & $46(7.5)$ & $59(13.2)$ & $7(10.3)$ & \\
\hline & I do not have a sister & $314(51.5)$ & $229(51.0)$ & $30(44.1)$ & \\
\hline \multirow{3}{*}{ PMS } & Yes & $421(69.0)$ & $273(60.8)$ & $21(30.9)$ & \multirow{3}{*}{$<0.005^{*}$} \\
\hline & No & $78(12.8)$ & $83(18.5)$ & $33(48.5)$ & \\
\hline & I do not know & $111(18.2)$ & $93(20.7)$ & $14(20.6)$ & \\
\hline \multirow{3}{*}{ Age of menarche } & $\leq 12$ years & $316(51.8)$ & $205(45.7)$ & $21(30.9)$ & \multirow{3}{*}{$<0.005^{*}$} \\
\hline & $13-14$ years & $248(40.7)$ & $193(43.0)$ & $36(52.9)$ & \\
\hline & $\geq 15$ years & $46(7.5)$ & $51(11.3)$ & $11(16.2)$ & \\
\hline \multirow{3}{*}{ Healthy diet } & Yes & $259(42.5)$ & $215(47.9)$ & $36(52.9)$ & \multirow{3}{*}{0.068} \\
\hline & No & $218(35.7)$ & $154(34.3)$ & $15(22.1)$ & \\
\hline & I do not know & $133(21.8)$ & $80(17.8)$ & $17(25.0)$ & \\
\hline \multirow{4}{*}{ Stress } & Everyday & $164(26.9)$ & $100(22.3)$ & $13(19.1)$ & \multirow{4}{*}{$0.005^{*}$} \\
\hline & A few times a week & $273(44.7)$ & $177(39.4)$ & $28(41.2)$ & \\
\hline & A few times a month & $134(22.0)$ & $124(27.6)$ & $16(23.5)$ & \\
\hline & Rarely & $39(6.4)$ & $48(10.7)$ & $11(16.2)$ & \\
\hline \multirow{6}{*}{ Self-esteem } & I am perfect, I love my appearance & $16(2.6)$ & $7(1.6)$ & $3(4.4)$ & \multirow{6}{*}{$0.042^{*}$} \\
\hline & $\begin{array}{c}\text { I accept myself as I am, although I am aware of my } \\
\text { imperfections }\end{array}$ & $271(44.4)$ & $225(50.1)$ & $41(60.3)$ & \\
\hline & $\begin{array}{l}\text { When I have a good day, I do not have much to complain } \\
\text { about, but sometimes I feel worse about myself }\end{array}$ & $262(42.9)$ & $175(39.0)$ & $18(26.5)$ & \\
\hline & It does not matter how I look-I don't care & $6(1.0)$ & $8(1.8)$ & $1(1.5)$ & \\
\hline & I think I am ugly, I cannot look at myself & $40(6.6)$ & $19(4.2)$ & $2(2.9)$ & \\
\hline & Other & $15(2.5)$ & $15(3.3)$ & $3(4.4)$ & \\
\hline \multirow{2}{*}{ Exercise } & Yes & $311(51.0)$ & $260(57.9)$ & $42(61.8)$ & \multirow{2}{*}{$0.037^{*}$} \\
\hline & No & $299(49.0)$ & $189(42.1)$ & $26(38.2)$ & \\
\hline \multirow{7}{*}{ Frequency of exercises } & Everyday & $21(3.4)$ & $15(3.3)$ & $3(4.4)$ & \multirow{7}{*}{0.5636} \\
\hline & A few times a week & $196(32.0)$ & $165(36.7)$ & $26(38.2)$ & \\
\hline & Once a week & $84(13.8)$ & $71(15.8)$ & $10(14.7)$ & \\
\hline & Once a month & $14(2.3)$ & $9(2.0)$ & $1(1.5)$ & \\
\hline & Seasonally & $84(13.8)$ & $51(11.4)$ & $12(17.7)$ & \\
\hline & Rarely & $94(15.4)$ & $51(11.4)$ & $6(8.8)$ & \\
\hline & Never & $118(19.3)$ & $87(19.4)$ & $10(14.7)$ & \\
\hline \multirow{3}{*}{ BMI } & $<18.5$ & $59(9.7)$ & $35(7.8)$ & $6(8.8)$ & \multirow{3}{*}{0.271} \\
\hline & $18.5-24.9$ & $474(77.7)$ & $341(75.9)$ & $52(76.5)$ & \\
\hline & $>25$ & $77(12.6)$ & $73(16.3)$ & $10(14.7)$ & \\
\hline \multirow{6}{*}{ Alcohol intake } & Everyday & $2(0.3)$ & $2(0.5)$ & $0(0.0)$ & \multirow{6}{*}{0.3602} \\
\hline & A few times a week & $53(8.7)$ & $34(7.6)$ & $4(5.9)$ & \\
\hline & Several times a month & $177(29.0)$ & $156(34.7)$ & $29(42.7)$ & \\
\hline & During celebrations, parties & $263(43.1)$ & $177(39.4)$ & $22(32.3)$ & \\
\hline & Never & $34(5.6)$ & $16(3.6)$ & $3(4.4)$ & \\
\hline & Very rarely & $81(13.3)$ & $64(14.2)$ & $10(14.7)$ & \\
\hline \multirow{2}{*}{ Smoking } & Yes & $123(20.2)$ & $95(21.2)$ & $14(20.6)$ & \\
\hline & No & $487(79.8)$ & $354(78.8)$ & $54(79.8)$ & 5 \\
\hline
\end{tabular}

Abbreviations: PG, women with dysmenorrhea during every cycle, SG, women with dysmenorrhea occasionally, WG, women without dysmenorrhea, PMS, premenstrual syndrome, and BMI, body mass index. ${ }^{*}$ Statistically significant variables.

dysmenorrhea was close to the expected value (grey). The occurrence of dysmenorrhea in sisters of the respondents from the WG group was also close to the expected value. The multivariate analysis, conducted using contingency tables for the study parameters, showed a statistically significant relationship $p<0.001$ (Figure 2).
3.3.3. Premenstrual Syndrome (PMS). The correspondence analysis was conducted to determine the relationship between responses of the respondents to the questions regarding the perception of dysmenorrhea and the occurrence of PMS. It has been shown that there is a strong relationship between the responses: "yes" to the 


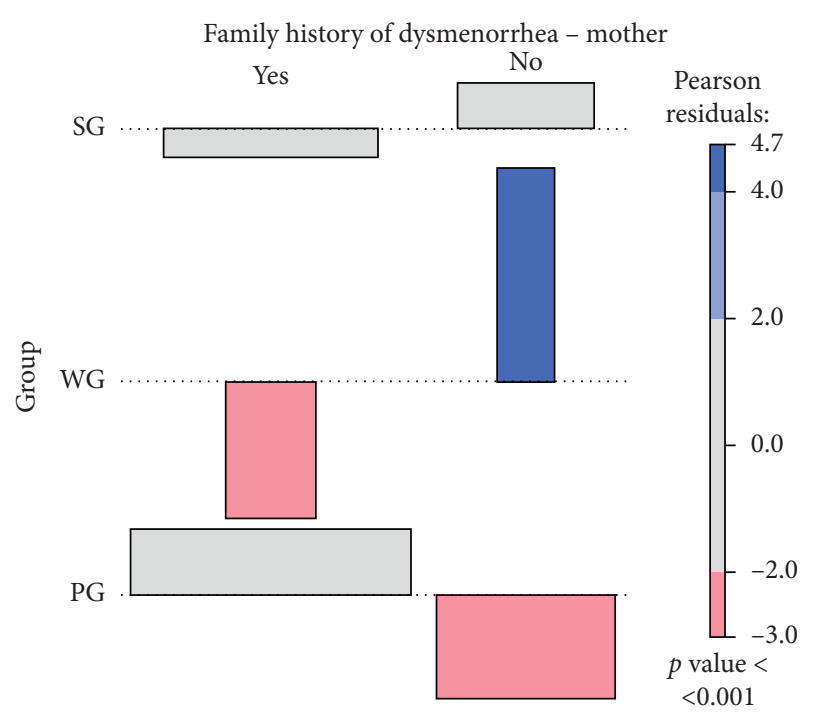

Figure 1: A diagram of multidimensional data association for respondents from the groups (PG, SG, and WG) and the occurrence of dysmenorrhea in the respondents' mothers (answers: yes, no). A significant statistical relationship $p<0.001$ was found between the multidimensional data. PG, women with dysmenorrhea during every cycle, SG, women with dysmenorrhea occasionally, and WG, women without dysmenorrhea.

occurrence of dysmenorrhea and "yes" to suffering from PMS. A strong relationship was also found between the "I do not know" answer to the occurrence of PMS and the answer "sometimes" in the question about dysmenorrhea (Figure 3). The OR for PMS in the women from the PG group in relation to the WG group was 2.27 (1.1-4.5 CI). Pearson's chi-squared test showed a statistically significant relationship between the perception of pain and the occurrence of PMS $(p<0.005)$ (Table 3).

3.3.4. Self-Esteem. The correspondence analysis performed for self-esteem vs. dysmenorrhea showed a relationship between the answer "I think I am ugly, I cannot look at myself" and the occurrence of dysmenorrhea (Figure 4). Fisher's exact test detected that the relationship is statistically significant $(p=0.042)$ (Table 3) (All the questions are included in Appendix A).

3.3.5. Age of Menarche. In our study, 542 (48\%) women had their first menstruation at $\leq 12$. The age of menarche in each of the analysed groups was not normally distributed. The Kruskal-Wallis test showed the relation between the age of first menstruation and the prevalence of dysmenorrhea $(p<0.005)$ (Table 3). Post hoc tests for the Kruskal-Wallis analysis revealed statistically significant differences between all groups: $p=0.011$ for PG-SG, $p=0.002$ for PG-WG, and $p=0.045$ for WG-SG (Figure 5).

3.3.6. Frequency of Stress. It was shown that 164 (26.9\%) women from the PG group experienced stress every day, 273 $(44.7 \%)$ several times a week, $134(22.0 \%)$ several times a months, and only $39(6.4 \%)$ of those questioned in this group

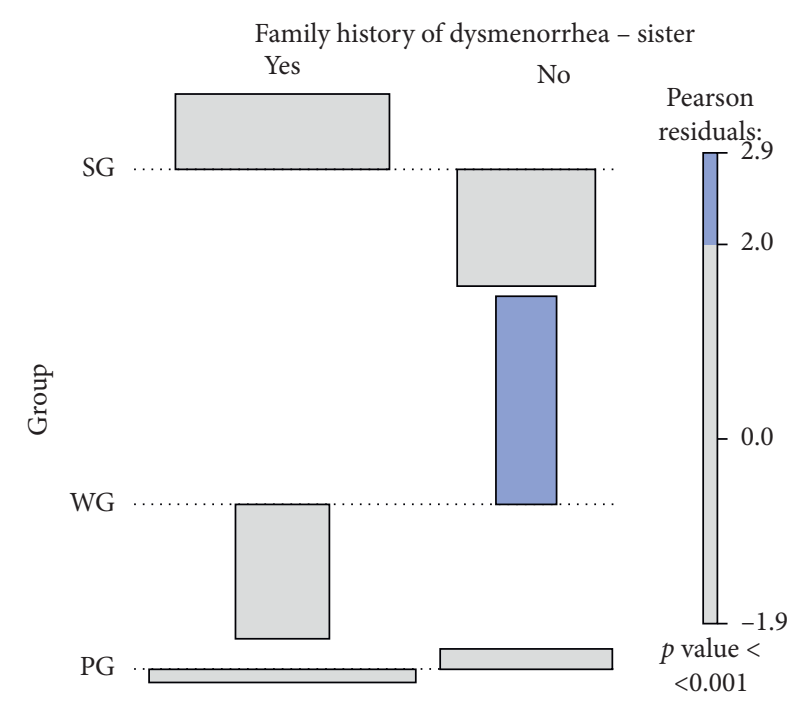

FIgURE 2: A diagram of multidimensional data association for respondents from individual groups (PG, SG, and WG) and the occurrence of dysmenorrhea in sisters of the respondents (answers: yes, no). A significant statistical relationship $p<0.001$ was found between the multidimensional data. PG, women with dysmenorrhea during every cycle, SG, women with dysmenorrhea occasionally, and WG, women without dysmenorrhea.

claimed to rarely experience stress. Similar results were obtained in the SG group: 100 (22.3\%), 177 (39.4\%), 124 (27.6\%), and $48(10.7 \%)$, respectively. In the WG group, it was observed that $13(19.1 \%)$ of respondents experienced stress every day, 28 (41.2\%) several times a week, 16 (23.5\%) several times a month, and $11(16.2 \%)$ rarely. The result of the independence test for the examined groups of variables is statistically significant $(p=0.005)$ (Table 3$)$.

3.3.7. Diet, Physical Activity, Alcohol Intake, Cigarette Smoking, and BMI. Women who reported no physical activity, significantly more often experienced dysmenorrhea $(p=0.037)$. However, the frequency of physical exercise did not significantly affect dysmenorrhea $(p=0.564)$. The women were asked "How often do you exercise?" and could choose an answer from the following: "every day," "several times a week," "once a week," "once a month," "seasonally," "rarely," and "never" (Table 3).

The respondents answered the question whether their diet was healthy. There were three answers to choose from: "yes," "no," and "I do not know." In the studied group of respondents, there was no statistical significance between diet and dysmenorrhea ( $p=0.068)$, as well as between BMI and dysmenorrhea $(p=0.271)$. Based on the respondents' answers, it was concluded that cigarette smoking did not affect the occurrence of dysmenorrhea $(p=0.924)$. Moreover, the analysis showed that the frequency of alcohol intake did not affect the frequency of dysmenorrhea ( $p=0.396)$. The answer options were the following: "I drink alcohol every day", "I drink alcohol several times a month,"."I drink alcohol at parties," "I rarely drink alcohol," and "I never drink alcohol" (Table 3). 


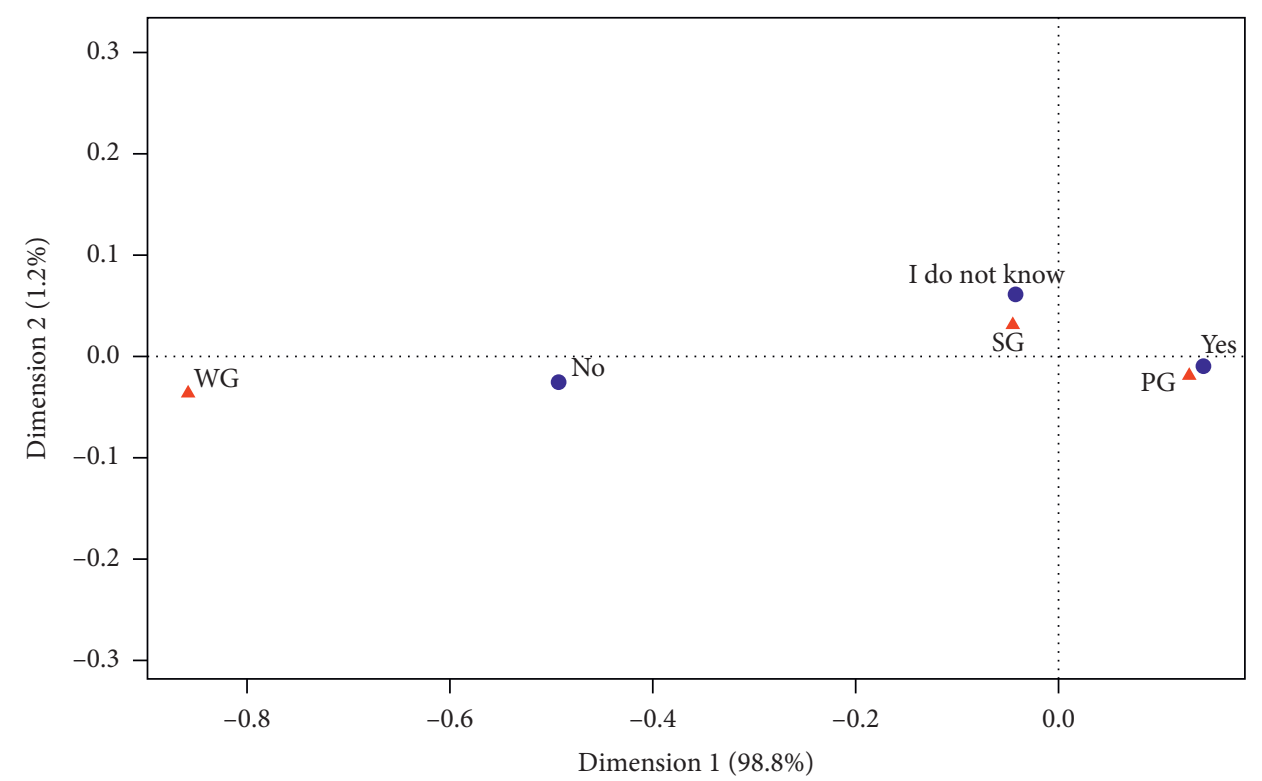

FIGURE 3: The analysis of correspondence regarding premenstrual syndrome and dysmenorrhea among the studied female respondents. PG, women with dysmenorrhea during every cycle, SG, women with dysmenorrhea occasionally, and WG, women without dysmenorrhea.

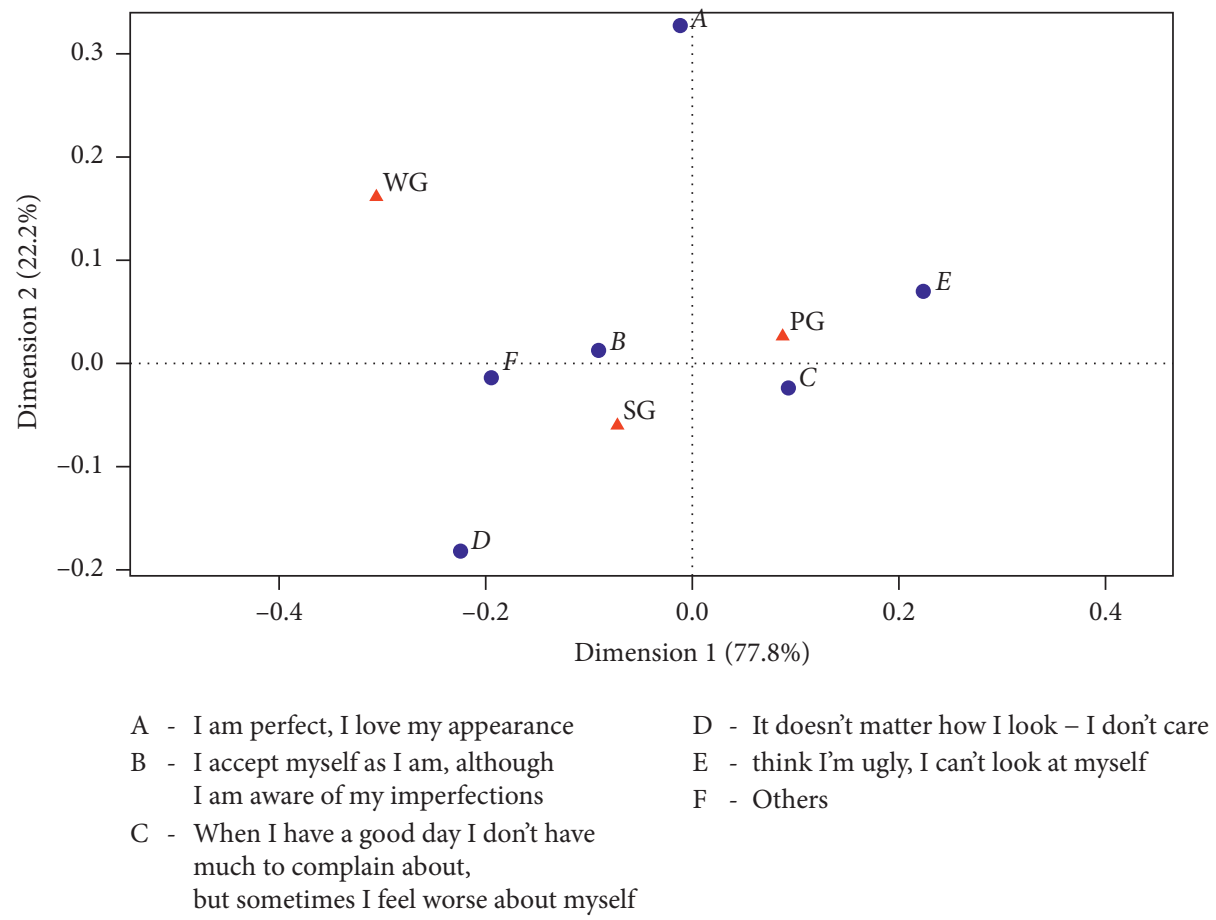

FIGURE 4: The analysis of correspondence regarding self-esteem and dysmenorrhea among the studied female respondents. The questions are included in Appendix A. PG, women with dysmenorrhea during every cycle, SG women with dysmenorrhea occasionally, and WG, women without dysmenorrhea.

\section{Discussion}

In the studied group of respondents, no statistically significant relationship was found between diet, BMI, frequency of alcohol intake, cigarette smoking, and dysmenorrhea in Polish women. Our results confirm previous reports of other researchers, that amount of alcohol intake had no significant effect on the occurrence of dysmenorrhea [30]. A healthy or unhealthy diet also does not affect the frequency of dysmenorrhea in the studied women. However, according to the literature, an unhealthy diet could predispose women to the occurrence of dysmenorrhea [31, 32].

In our studied group, there was no relationship between $\mathrm{BMI}$ and dysmenorrhea. This might be due to the fact that 


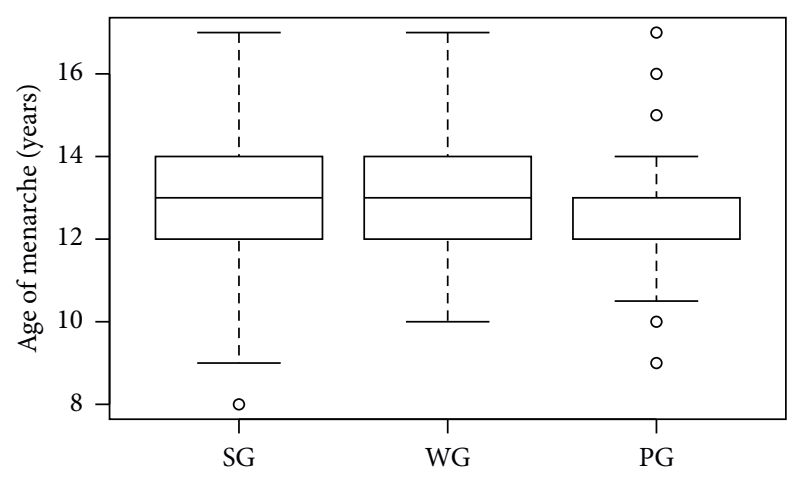

Figure 5: Age of the first menstruation and dysmenorrhea in respondents. A statistically significant difference was revealed between the PG and SG groups ( $p=0.011)$, as well as between the PG and WG ( $p=0.002)$, and between the WG and SG ( $p=0.045)$. PG, women with dysmenorrhea during every cycle, SG, women with dysmenorrhea occasionally, and WG, women without dysmenorrhea.

the majority of women who participated in the research presented BMI values from 18.5 to $24.9 \mathrm{~kg} / \mathrm{m}$ [2]. Those values are regarded as normal weight [24]. There were few participants, in the research, whose BMI would indicate being either underweight or overweight. Our results are consistent with the research by Hailemeskel et. al. [19], where the majority of respondents' BMI values were normal [19]. In contrast, several studies have shown that an abnormal BMI could predispose women to dysmenorrhea $[5,33]$. The researchers observed that obese women who have a significant accumulation of visceral fat tissue, most frequently struggle with painful menstrual periods [6].

Our study found that dysmenorrhea affects $94 \%$ of respondents. We have observed that some factors appear more frequently in women with dysmenorrhea. The statistically significant factor was the occurrence of dysmenorrhea in the family-in mothers and sisters. The respondents in the group PG confirmed that their mothers and sisters often suffered from dysmenorrhea. Pearson's chi-squared test and the multidimensional data analysis, conducted using contingency tables, showed a statistically significant relationship between the occurrence of dysmenorrhea in the mothers and sisters of the respondents. Our result is supported by other studies [20,34]. Polat et al. showed that the daughters of women who suffered from menstrual complaints were also affected by menstrual discomfort [34]. The authors suggest that the prevalence of dysmenorrhea among daughters could be associated with behaviours learnt from mothers [20].

Premenstrual syndrome (PMS) is a syndrome present during the luteal phase of the menstrual cycle and subsides at the time of menstrual bleeding, and it is characterized by psychological and physical symptoms, such as breast hypersensitivity, oedema, irritability, and depressed mood [35-39]. Our research demonstrates that the prevalence of PMS was significantly higher in the PG group. Premenstrual syndrome was detected in $83.8 \%$ of women with dysmenorrhea and only in $39.3 \%$ of women who had not reported dysmenorrhea. A similar conclusion that PMS often accompanies dysmenorrhea was reported by Kitamura et al. [40]. A correlation between PMS and dysmenorrhea was observed in girls aged 15-19 [40].

Our study also showed that the age of the first menstruation had a significant relationship to the occurrence of dysmenorrhea. As many as $48 \%$ of the respondents had their first menstruation at the age of $\leq 12$. Our study results are consistent with the findings of other authors who demonstrated that the occurrence of dysmenorrhea increases with a lower age of the first menstruation $[8,18,23]$. On the other hand, there are studies showing no relationship between the lower age of the first menstrual period and dysmenorrhea [20].

Self-esteem was another statistically significant factor analysed in our research. We have shown a significant relationship between the answer "I think I am ugly, I cannot look at myself" and the occurrence of dysmenorrhea. To our knowledge, this is the first research into self-esteem in the context of dysmenorrhea. The significance of our results indicates a need for further research into the impact of selfesteem on the occurrence of dysmenorrhea.

Our results confirm that the physical activity has an impact on the occurrence of dysmenorrhea. Various researchers presented their own training programs to reduce dysmenorrhea in women $[39,40]$. The set of exercises proposed by Kitamuraet al. [40] reduced the severity of dysmenorrhea, but also had an influence on the duration and amount of blood loss during menstruation. In addition, Kannan et. al. [41] demonstrated that the physical activity has an impact on the concentrations of progesterone, prostaglandin, and the tumour necrosis factor.

Our study showed that stress significantly contributes to dysmenorrhea. Almost 30\% of women who suffered from dysmenorrhea during every cycle claimed to have been experiencing stress every day, and only $6.8 \%$ of women in this group rarely suffered from pain. In the group of women without dysmenorrhea, 20\% experienced stress and almost 17\% were rarely stressed. For comparison, in a study performed in India, stress affected only $24.4 \%$ of women with dysmenorrhea [42]. In our study group, $54.8 \%$ were students. Previous studies have indicated that the life of Polish students is stressful [43]. In Poland, within the last 20 years, the number of university students has increased more than $400 \%$. Moreover, since the political and economic transformation in Poland, more and more students combine studying with work. It was shown that Polish students are at the top of the European ranking concerning the hardestworking young people who study and work simultaneously [44].

\section{Study Limitations}

The present study has some limitations that we would like to address. First, due to the questionnaire's distribution method, the sample cannot be treated as a representative for the whole population of Polish women. The study mostly reflects the condition of young (20-25) women from urban areas. Second, we cannot verify the responses of women with dysmenorrhea. Further cohort and longitudinal studies are being conducted to verify our findings and to garner a deeper understanding. 


\section{Conclusion}

The study points to the fact that the problem of dysmenorrhea affects many Polish women. Women with dysmenorrhea were characterized with a family history of dysmenorrhea, occurrence of PMS, early age of menarche, stressful lifestyle, lack of physical activity, and low self-esteem. Therefore, we suggest that assessment of factors that contribute to dysmenorrhea is needed. Understanding the aetiology and factors responsible for dysmenorrhea will allow a precise diagnosis to be made and thus the application of more effective therapeutic methods.

\section{Appendix}

Questionnaire-English version

(1) Weight $(\mathrm{kg})$

(2) Height (m)

(3) Age (years)

(4) Place of origin
(a) Rural
(b) Urban

(5) Education
(a) School student
(b) Student
(c) Primary education
(d) Secondary education
(e) Higher education

(6) Age of menarche (your first menstruation)?

(7) Are your menstrual cycles regular (21-35 days)?
(a) Yes
(b) No

(8) Do you suffer from menstrual pain (dysmenorrhea)?
(a) Yes, dysmenorrhea during every or from time to time menstruation
(b) No, without dysmenorrhea

(9) Has your mother suffered from menstrual pain?
(a) Yes
(b) No
(c) I do not know

(10) Has your sister (s) suffered from menstrual pain?
(a) Yes
(b) No
(c) I do not know
(d) I do not have any sisters

(11) On a scale (NPRS) from 0 to 10 , how strongly do you feel menstrual pain at the worst moment of the cycle?

(12) Do you suffer from premenstrual syndrome (PMS)?
(a) Yes
(b) No
(c) I do not know

(13) Do you do some sports?
(a) Yes
(b) No

(14) How often do you exercise?
(a) Every day
(b) A few times a week
(c) Once a week
(d) Once a month
(e) Seasonally
(f) Very rarely
(g) I do not exercise

(15) Do you think, that your diet is healthy?
(a) Yes
(b) No
(c) I do not know

(16) Do you smoke?
(a) Yes
(b) No

(17) How often do you drink alcohol?
(a) Everyday
(b) A few times a week
(c) Several times a month
(d) During celebrations, parties
(e) Very rarely
(f) Never

(18) How do you perceive yourself?
(a) I am perfect. I love my appearance
(b) I accept myself as I am, although I am aware of my imperfections
(c) When I have a good day, I do not have much to complain about, but sometimes I feel worse about myself
(d) It does not matter how I look-I do not care
(e) I think I am ugly, I cannot look at myself
(f) Others

(19) How often to you experience stress?
(a) Every day
(b) A few times a week
(c) Several times a month
(d) I experience stress rarely

\section{Data Availability}

The data used to support the findings of this study are included within the article.

\section{Disclosure}

The authors have no relevant affiliations or financial involvement with any organization or entity with a financial 
interest in or financial conflict with the subject matter or materials discussed in the manuscript. This includes employment, consultancies, honoraria, stock ownership or options, expert testimony, grants or patents received or pending, or royalties.

\section{Conflicts of Interest}

The authors declare that they have no conflicts of interest.

\section{Authors' Contributions}

Zofia Barcikowsk and Karolina Wójcik-Bilkiewicz contributed equally to this work.

\section{Acknowledgments}

This work was supported by grant from Medical University of Gdańsk (ST-02-0108/07/780) in Poland.

\section{References}

[1] M. Proctor and C. Farquhar, "Diagnosis and management of dysmenorrhea," BMJ, vol. 332, no. 7550, pp. 1134-1138, 2006.

[2] S. Iacovides, I. Avidon, and F. C. Baker, "What we know about primary dysmenorrhea today: a critical review," Human Reproduction Update, vol. 21, no. 6, pp. 762-778, 2015.

[3] G. Mrugacz, C. Grygoruk, P. Sieczyński et al., "Etiopathogenesis of dysmenorrhea," Developmental Period Medicine, vol. 17, no. 1, pp. 85-59, 2013.

[4] P. Latthe, M. Latthe, L. Say, M. Gülmezoglu, and K. S. Khan, "WHO systematic review of prevalence of chronic pelvic pain: a neglected reproductive health morbidity," BMC Public Health, vol. 6, no. 1, pp. 1-7, 2006.

[5] I. Teul, K. Kliś, K. Jarzębak, and I. Wronka, “The prevalence and correlates of menstrual pain in healthy university students," Annales Academiae Medicae Stetinensis, vol. 60, no. 2, pp. 89-94, 2014.

[6] M. Zurawiecka and I. Wronka, "Association of primary dysmenorrhea with anthropometrical and socioeconomic factors in polish university students," Journal of Obstetrics and Gynaecology Research, vol. 44, no. 7, pp. 1259-1267, 2018.

[7] N. H. Cha and S. R. Sok, "Effects of auricular acupressure therapy on primary dysmenorrhea for female high school students in South Korea," Journal of Nursing Scholarship, vol. 48 , no. 5, pp. 508-516, 2016.

[8] G. Grandi, S. Ferrari, A. Xholli et al., "Prevalence of menstrual pain in young women: what is dysmenorrhea?" Journal of Pain Research, vol. 5, pp. 169-174, 2012.

[9] N. Motahari-Tabari, M. A. Shirvani, and A. Alipour, "Comparison of the effect of stretching exercises and mefenamic acid on the reduction of pain and menstruation characteristics in primary dysmenorrhea: a randomized clinical trial," Oman Medical Journal, vol. 32, no. 1, pp. 47-53, 2017.

[10] S. A. Ryan, "The treatment of dysmenorrhea," Pediatric Clinics of North America, vol. 64, no. 2, pp. 331-342, 2017.

[11] H. Y. Dogru, A. Z. Ozsoy, N. Karakus, I. B. Delibas, C. K. Isguder, and S. Yigit, "Association of genetic polymorphisms in TNF and MIF gene with the risk of primary dysmenorrhea," Biochemical Genetics, vol. 54, no. 4, pp. 457-466, 2016.
[12] L.-C. Lee, C.-H. Tu, L.-F. Chen et al., "Association of brainderived neurotrophic factor gene Val66Met polymorphism with primary dysmenorrhea," PLoS One, vol. 9, no. 11, p. e112766, 2014.

[13] A. V. Jones, J. R. F. Hockley, C. Hyde et al., "Genome-wide association analysis of pain severity in dysmenorrhea identifies association at chromosome 1p13.2, near the nerve growth factor locus," Pain, vol. 157, no. 11, pp. 2571-2581, 2016.

[14] Z. Barcikowska, E. Rajkowska-Labon, M. E. Grzybowska, R. Hansdorfer-Korzon, and K. Zorena, "Inflammatory markers in dysmenorrhea and therapeutic options," International Journal of Environmental Research and Public Health, vol. 17, no. 4, pp. 1191-1214, 2020.

[15] M. E. Sahin, E. Sahin, Y. Madendag et al., "The effect of anterior uterocervical angle on primary dysmenorrhea and disease severity," Pain Research and Management, vol. 2018, Article ID 9819402, 5 pages, 2018.

[16] M. Y. Dawood, "Dysmenorrhea and prostaglandins," in Gynecologic Endocrinology, J. J. J. Gold, Ed., Plenum Publishing Corporation, New York, NY, USA, pp. 405-421, 1987.

[17] V. Lundström and K. Green, "Endogenous levels of prostaglandin F2 $\alpha$ and its main metabolites in plasma and endometrium of normal and dysmenorrheic women," American Journal of Obstetrics and Gynecology, vol. 130, no. 6, pp. 640-646, 1978.

[18] C. Balbi, R. Musone, A. Menditto et al., "Influence of menstrual factors and dietary habits on menstrual pain in adolescence age," European Journal of Obstetrics \& Gynecology and Reproductive Biology, vol. 91, no. 2, pp. 143-148, 2000.

[19] S. Hailemeskel, A. Demissie, and N. Assefa, "Primary dysmenorrhea magnitude, associated risk factors, and its effect on academic performance: evidence from female university students in Ethiopia," International Journal of Women's Health, vol. 8, pp. 489-496, 2016.

[20] N. Ozerdogan, D. Sayiner, U. Ayranci, A. Unsal, and S. Giray, "Prevalence and predictors of dysmenorrhea among students at a university in Turkey," International Journal of Gynecology \& Obstetrics, vol. 107, no. 1, pp. 39-43, 2009.

[21] N. Habibi, M. S. L. Huang, W. Y. Gan, R. Zulida, and S. M. Safavi, "Prevalence of primary dysmenorrhea and factors associated with its intensity among undergraduate students: a cross-sectional study," Pain Management Nursing, vol. 16, no. 6, pp. 855-861, 2015.

[22] M. Faramarzi and H. Salmalian, "Association of psychologic and nonpsychologic factors with primary dysmenorrhea," Iranian Red Crescent Medical Journal, vol. 16, no. 8, Article ID e16307, 2014.

[23] A. Pejcic and S. Jankovic, "Risk factors for dysmenorrhea among young adult female university students," Annali dell'Istituto Superiore di Sanità, vol. 52, no. 1, pp. 98-103, 2016.

[24] World Health Organization, Obesity: Preventing and Managing the Global Epidemic WHO Technical Report Series, World Health Organization, Geneva, Switzerland, 2000.

[25] M. P. Jensen, J. A. Turner, J. M. Romano, and L. D. Fisher, "Comparative reliability and validity of chronic pain intensity measures," Pain, vol. 83, no. 2, pp. 157-162, 1999.

[26] H. Breivik, P. C. Borchgrevink, S. M. Allen et al., "Assessment of pain," British Journal of Anaesthesia, vol. 101, no. 1, pp. 17-24, 2008.

[27] R Core Team, A Language and Environment for Statistical Computing, R Core Team, Vienna, Austria, 2018, https://www. r-project.org/.

[28] M. Friendly, H. Turner, A. Zeileis, D. Murdoch, and D. Firth, vcdExtra: "vcd" Extensions and Additions. R Package Version 0.7-1, 2017, https://cran.r-project.org/package=vcdExtra\%0A\%0A. 
[29] O. Nenadic and M. Greenacre, "Correspondence analysis in R, with two- and three-dimensional graphics: the ca package," Journal of Statistical Software, vol. 20, no. 3, pp. 1-14, 2007.

[30] T. Makowiec-Da̧browska, E. Sprusińska, W. Hanke, Z. Radwan-Włodarczyk, and W. Koszada-Włodarczyk, "Perimenstrual complaints: is this problem to be handed by occupational medicine physican?" Medical Prestigious, vol. 54, no. 6, pp. 511-519, 2003.

[31] I. Monday, P. Anthony, E. Olunu et al., "Prevalence and correlation between diet and dysmenorrhea among high school and college students in saint vincent and grenadines," Open Access Macedonian Journal of Medical Sciences, vol. 7, no. 6, pp. 920-924, 2019.

[32] Z. Bajalan, Z. Alimoradi, and F. Moafi, "Nutrition as a potential factor of primary dysmenorrhea: a systematic review of observational studies," Gynecologic and Obstetric Investigation, vol. 84, no. 3, pp. 209-224, 2019.

[33] H. Ju, M. Jones, and G. D. Mishra, "A U-shaped relationship between body mass index and dysmenorrhea: a longitudinal study," PLoS One, vol. 10, no. 7, 13 pages, 2015.

[34] A. Polat, H. Celik, B. Gurates et al., "Prevalence of primary dysmenorrhea in young adult female university students," Archives of Gynecology and Obstetrics, vol. 279, no. 4, pp. 527-532, 2009.

[35] A. Dirkvand-Moghdam, K. Sayehmiri, A. Delpisheh, and K. Sattar, "Epidemiology of premenstrual syndrome: a systematic review and meta-analysis study," Journal of Clinical and Diagnostic Research, vol. 8, no. 2, pp. 106-109, 2014.

[36] M. Olajossy and A. Gerhant, "Premenstrual syndrome and premenstrual dysphoric disorder:problem on the border of psychiatry and gynecology," Current Problems of Psychiatry, vol. 12, no. 2, pp. 163-170, 2011.

[37] H. H. Oo, M. T. Sein, O. Mar, and A. Aung, "Assessment of premenstrual syndrome among reproductive aged Myanmar women," Asian Journal of Medical Sciences, vol. 7, no. 4, pp. 39-43, 2016.

[38] A. R. Kroll-Desrosiers, A. G. Ronnenberg, S. E. Zagarins, S. C. Houghton, B. B. Takashima-Uebelhoer, and E. R. Bertone-Johnson, "Recreational physical activity and premenstrual syndrome in young adult women: a crosssectional study," PLoS One, vol. 12, no. 1, Article ID e0169728, 2017.

[39] J. Hoyer, I. Burmann, M.-L. Kieseler et al., "Menstrual cycle phase modulates emotional conflict processing in women with and without premenstrual syndrome (PMS) - a pilot study," PLoS One, vol. 8, no. 4, Article ID e59780, 2013.

[40] M. Kitamura, T. Takeda, S. Koga, S. Nagase, and N. Yaegashi, "Relationship between premenstrual symptoms and dysmenorrhea in Japanese high school students," Archives of Women's Mental Health, vol. 15, no. 2, pp. 131-133, 2012.

[41] P. Kannan, K. K. Cheung, and B. W. M. Lau, "Does aerobic exercise induced-analgesia occur through hormone and inflammatory cytokine-mediated mechanisms in primary dysmenorrhea?" Medical Hypotheses, vol. 123, pp. 50-54, 2019.

[42] V. B. Waghachavare, G. B. Dhumale, Y. R. Kadam, and A. D. Gore, "A study of stress among students of professional colleges from an urban area in India," Sultan Qaboos University Medical Journal, vol. 13, no. 3, pp. 422-429, 2013.

[43] K. Brożyna, A. Radzka, J. Tkaczyk, K. Ciechański, and H. Piecewicz-Szczęsna, "Stress among medical students in Poland," J Educ Heal Sport, vol. 8, no. 8, pp. 171-179, 2018.

[44] J. Lenart, "Student i praca. Historia i współczesność," Przegląd Pedagog, vol. 2, pp. 117-129, 2014. 